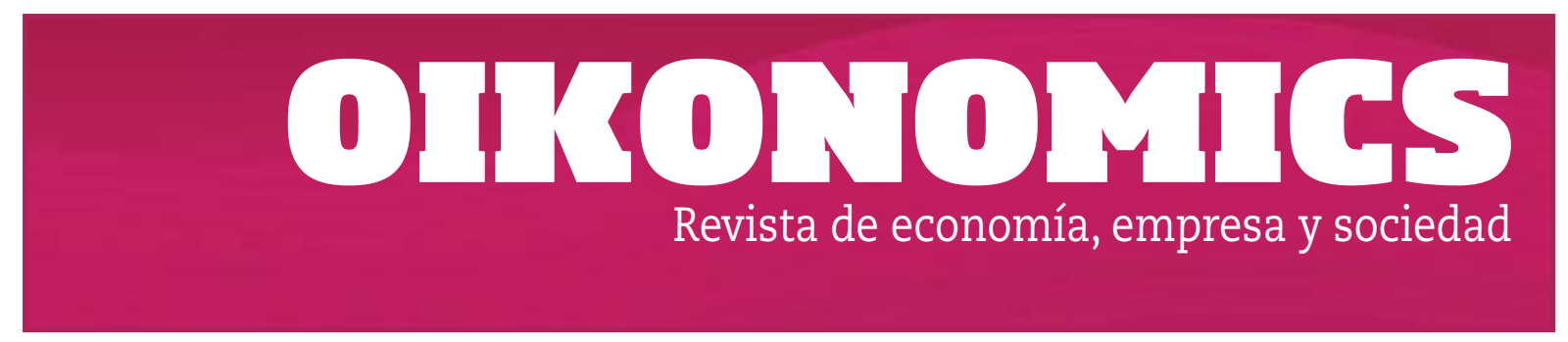

MIRANDO HACIA EL FUTURO

\title{
Logística y cadena de suministro en la nueva era digital
}

\section{Marta Viu Roig}

Directora del máster de Dirección de operaciones y logística integral (UOC)

La conectividad ya no es un lujo y se ha convertido en una necesidad principalmente para las empresas. La creciente aceleración del ritmo de los cambios tecnológicos hace que la forma en que los datos se crean, se transportan, se analizan y las consecuentes acciones que generan supongan tanto una oportunidad como una amenaza para dichas empresas y para el conjunto de la sociedad.

Mirando hacia el futuro, ya no podemos limitar el enfoque empresarial a una simple evolución del negocio y la tecnología, sino que nos debemos adaptar a una revolución en la forma de ver las cosas. En el campo logístico, las empresas no solo deben hacer las cosas mejor, sino también de forma distinta para seguir compitiendo en mercados cada día más complicados y exigentes. Las empresas tienen que conectar su cadena de suministro más allá de sus actuales límites operativos si desean mantenerse competitivas en una nueva era digital, que supera la previa basada en las tecnologías e internet no interactivos. Aspectos como una función logística cada vez más autónoma (vehículos sin conductor, drones o robots), el acercamiento de la producción al cliente con la impresión 3D, el internet de las cosas (loT, sensores que conectan los objetos físicos con internet), la realidad aumentada (por ejemplo, mediante el uso de las smartglasses en actividades de picking), la gran cantidad de datos generados por el big data o el blockchain, la revolución de la logística de distribución a raíz del fenómeno de Amazon hacia la entrega de cualquier producto en cualquier momento y en cualquier lugar, la omnicanalidad y la necesidad de combinar servicios individualizados cada vez más rápidos con una cadena de suministro más justa, más responsable y sostenible (logística colaborativa, intermodalidad, economía circular...) son solamente algunos de los retos y 
tendencias que impactarán o incluso revolucionarán la industria logística en esta nueva era digital.

Como resultado de este proceso de transformación digital de la economía, el sector logístico se ha convertido en un motor económico y generador de ocupación, especialmente, por los rápidos avances del comercio electrónico (eCommerce). Según el informe Futuro del Trabajo en España (Adecco, 2016), el sector logístico será uno de los sectores que liderará la creación de empleo en el período 2020-2025. En la misma línea, el informe Ocupacions més demandades al sector de la logística (Barcelona Activa, 2015), muestra que el sector logístico siguió ganando importancia en la economía española. Respecto al año anterior, el volumen de negocio en el sector logístico se incrementó un 4,5 \% durante el primer semestre de 2015. En relación con la ocupación, el sector ocupó 874.400 personas durante el tercer trimestre del año 2015 (un 1,4% más que en 2014).

Por todo lo anterior, podemos afirmar que el futuro del sector logístico pasa por tres ejes clave que se analizan en este dosier: el desarrollo de infraestructuras competitivas y sostenibles; la innovación en tecnología y su aplicación a los distintos procesos logísticos; y la formación de profesionales con una visión integral de la logística y de la cadena de suministro que, al mismo tiempo, estén preparados para las nuevas tendencias detectadas en el sector.

Abre el monográfico el artículo «La logística del mañana: retos y oportunidades en la era digital». Eduard Álvarez y Marta Viu analizan los principales desafíos del sector logístico en la nueva era digital y se centran en la respuesta que la industria, las instituciones públicas y la comunidad educativa plantean para afrontar dichos retos en Europa.

Xavier Budet y Alexis Pérez, en los dos siguientes artículos, «La logística como fuente de valor añadido en el eCommerce» e «Innovaciones tecnológicas en la cadena de suministro aplicadas al eCommerce», nos presentan cómo la aparición de Amazon ha sacudido fuertemente el escenario competitivo obligando a fabricantes y distribuidores a dar una respuesta que satisfaga las nuevas expectativas de los compradores e iniciando una exigente carrera para dominar la cadena de valor y la experiencia del cliente final; asimismo, presentan un conjunto de tecnologías que están adquiriendo cada vez más relevancia en la cadena de suministro y cuál será su recorrido en los próximos años en función de los requerimientos del canal del eCommerce.

Siguiendo en el marco de la innovación tecnológica aplicada a la logística, José López Parada profundiza en el caso de la impresión 3D y en cómo esta puede representar un nuevo paradigma de producción, reduciendo la complejidad actual en los procesos de fabricación convencionales, en su artículo «Fabricación aditiva y transformación logística: evolución e impacto de la impresión 3D». 
Desde una óptica de innovación en procesos, Oriol Closa, en su artículo «Outsourcing de las actividades logísticas. ¿Cómo creamos valor añadido?», nos habla de las actividades logísticas que pueden ser externalizadas, los motivos de dicha externalización y los tipos de proveedores de servicios logísticos a utilizar si queremos realizar este proceso con éxito.

Milena Gómez y Laura Guitart et al., en «Las personas y la cadena de suministro", demuestran la importancia del estudio de los recursos humanos en la cadena de suministro, realizando un análisis en profundidad de las investigaciones, en estos dos campos en los últimos diecinueve años, que permite identificar y visibilizar sus potencialidades y sus carencias.

Concluye el monográfico Domingo Pérez, con el artículo «Ancho ferroviario y logística 4.0 en el corredor del Mediterráneo", en el que se ve cómo la convergencia de la tecnología ferroviaria de ejes de ancho variable para el transporte de mercancías con la logística 4.0, en los procesos de SCM (supply chain management), permitirá incrementar la productividad y la competitividad empresarial a escala internacional.

Con todo ello, este monográfico pretende integrar conceptos como innovación en tecnología, procesos, infraestructuras y recursos humanos, proporcionando distintas perspectivas de los retos y las oportunidades a los que se enfrentan los profesionales de la dirección logística y de la cadena de suministro en la nueva era digital. 


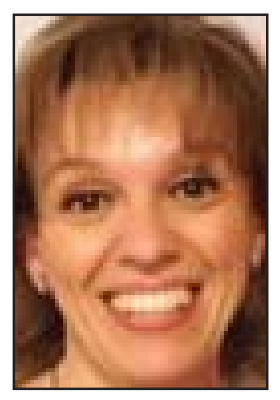

\section{Marta Viu Roig \\ Directora del máster de Dirección de operaciones y logística integral (UOC) mviu@uoc.edu}

Doctora en Empresa por la Universidad de Barcelona. Licenciada en Ciencias Económicas y Empresariales por la Universidad de Barcelona. Directora académica del máster propio de Logística integral y dirección de operaciones. Codirectora del executive master en Dirección de operaciones, logística \& SCM (EADA-UOC). Es miembro del grupo de investigación MeL, y su investigación se centra en los ámbitos de la logística y del eLearning.

Los textos publicados en esta revista están sujetas -salvo que se indique el contrario- a una licencia de Reconocimiento 3.0 España de Creative Commons. Podéis copiarlos, distribuirlos, comunicarlos públicamente y hacer obras derivadas siempre que reconozcáis los créditos de las obras (autoría, nombre de la revista, institución editora) de la manera especificada por los autores o por la revista. La licencia completa se puede consultar en http://creativecommons.org/licenses/by/3.0/es/deed.ca.

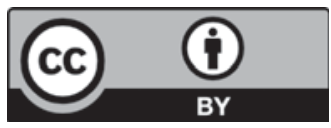

